\title{
High-pressure vapor + liquid equilibria for the binary system CO2 + (E)-2-hexenal
}

DOI:

10.1016/j.supflu.2020.105027

\section{Document Version}

Accepted author manuscript

Link to publication record in Manchester Research Explorer

\section{Citation for published version (APA):}

Villablanca-Ahues, R., López-Porfiri, P., Canales, R. I., \& de la Fuente, J. C. (2021). High-pressure vapor + liquid equilibria for the binary system CO2 + (E)-2-hexenal. The Journal of Supercritical Fluids, 168, [105027]. https://doi.org/10.1016/j.supflu.2020.105027

\section{Published in:}

The Journal of Supercritical Fluids

\section{Citing this paper}

Please note that where the full-text provided on Manchester Research Explorer is the Author Accepted Manuscript or Proof version this may differ from the final Published version. If citing, it is advised that you check and use the publisher's definitive version.

\section{General rights}

Copyright and moral rights for the publications made accessible in the Research Explorer are retained by the authors and/or other copyright owners and it is a condition of accessing publications that users recognise and abide by the legal requirements associated with these rights.

\section{Takedown policy}

If you believe that this document breaches copyright please refer to the University of Manchester's Takedown Procedures [http://man.ac.uk/04Y6Bo] or contact uml.scholarlycommunications@manchester.ac.uk providing relevant details, so we can investigate your claim.

\section{OPEN ACCESS}




\title{
High-pressure vapor + liquid equilibria for the binary system $\mathrm{CO}_{2}+(\mathrm{E})-2$-hexenal
}

\author{
Rafael Villablanca-Ahues ${ }^{a}$, Pablo López-Porfiri ${ }^{b}$, Roberto I. Canales ${ }^{c}$, and Juan C. de la \\ Fuente $^{a . *}$
}

${ }^{a}$ Laboratorio de Termodinámica de Procesos. Departamento de Ingeniería Química y Ambiental. Universidad Técnica Federico Santa María, Avda. España 1680, Valparaíso, Chile.

${ }^{b}$ School of Chemical Engineering and Analytical Sciences. Faculty of Science and Engineering. The University of Manchester, Manchester M13 9PL, United Kindom.

'Departamento de Ingeniería Química y Bioprocesos, Pontificia Universidad Católica de Chile, Avenida Vicuña Mackenna 4860, Santiago, Chile.

*Fax: (56-32) 2654478. Tel. (56-32) 2654221. E-mail: juan.delafuente@usm.cl

Submitted to The Journal of Supercritical Fluids

August 2020 


\begin{abstract}
The isothermal vapor + liquid equilibria of carbon dioxide + (E)-2-hexenal (a key apple aroma) was measured using a visual equilibrium cell with an analytic methodology. The selected isotherms were (313.2, 323.2 and 333.2) K, and the pressures assessed ranged from (2.2 to 9.8) MPa. The thermodynamic consistency of the experimental data was verified, and the uncertainties of the molar fractions of the vapor and liquid phases were estimated. The density and dynamic viscosity of pure (E)-2-hexenal were measured at $101.13 \mathrm{kPa}$ and temperatures from (292.2 to 353.2$) \mathrm{K}$. Two equations of state were selected to model the vapor + liquid equilibria. The Peng-Robinson with two different mixing rules, and the Perturbed Chain - Statistical Associating Fluid Theory. The phase envelopes showed a critical pressure, detected at carbon dioxide molar fractions $\geq 95 \% \mathrm{~mol} \cdot \mathrm{mol}^{-1}$.
\end{abstract}

Keywords: Vapor + liquid equilibria; carbon dioxide; (E)-2-hexenal; density; viscosity; experimental; modeling. 


\section{Introduction}

The aroma of apples is specific to the species and cultivar. The aroma contributes to the overall sensory quality of the fruit, and it is composed by a combination of approximately three hundred volatile organic compounds [1]. The mixture of nearly twenty chemical species, including aldehydes, alcohols, esters, and ketones, usually at very low concentrations, are considered to be the key blend that defines the typical aroma of apples [2]. The aldehyde (E)-2-hexenal (Figure 1) is identified as an essential aroma component for sensory impressions of freshness for green apples as well as in commercial apple juices [3-5].

The conventional procedures for the fractionation and recovery of key volatile organic compounds from concentrated or diluted fruit juice are based on the distillation process. The use of compressed countercurrent carbon dioxide $\left(\mathrm{CO}_{2}\right)$ as a solvent in a packed column has proven to be an efficient alternative for the extraction of apple aromas $[5,6]$. In this process, there is a continuous upward flow of a $\mathrm{CO}_{2}$-rich phase in contact with a downward flow of a liquid water-rich mixture with fruit juice. The operating temperature $(T)$ and pressure $(p)$ are above the critical values of the $\mathrm{CO}_{2}, T>T_{c}=304.1 \mathrm{~K}$ and $p>p_{c}=7.38 \mathrm{MPa}$. At the supercritical $(\mathrm{SC})$ condition, the $\mathrm{CO}_{2}$ reveals advantageous characteristics. In general, $\mathrm{SC}-\mathrm{CO}_{2}$ is selective, as well as a solvent with tunable properties with the temperature and pressure. In addition, the use of $\mathrm{SC}-\mathrm{CO}_{2}$ helps to eliminate the risk of thermal damage, and the solvent can be easily removed by decompression [7]. These two aspects are relevant for the fractionation and recovery of high-purity products in food, cosmetics, and for use in the pharmaceutical industry [8]. In order to design and optimize a process for the recovery of key volatile organic compounds using SC$\mathrm{CO}_{2}$, the main constraints are defined by the thermodynamic phase equilibria information. Specifically, experimental data as well as models that relate the temperature, pressure, and the mole fraction of the water-rich (liquid, $x_{\mathrm{i}}$ ) and $\mathrm{CO}_{2}$-rich (vapor, $y_{\mathrm{i}}$ ) phases at high-pressure equilibrium conditions are required

[9]. In addition, pure physicochemical properties of key aroma components such as vapor pressure $\left(p_{2}^{\text {Vap }}\right)$ 
[10], density $\left(\rho_{\mathrm{i}}\right)$ and dynamic viscosity $\left(\eta_{\mathrm{i}}\right)$ are also needed for a better understanding and modeling of the hydrodynamics process and mass transfer.

López-Porfiri et al., [9] analyzed the data of high-pressure vapor + liquid equilibria (VLE) available in the literature regarding systems containing aroma components and $\mathrm{CO}_{2}$. The literature suggests that the information could be organized into two main groups. First, the complex systems constituted for extracts of apple aroma components and $\mathrm{CO}_{2}$, and second, the model systems that include binary and multicomponent mixtures of one or two key aroma components, $\mathrm{CO}_{2}$, and eventually water [11]. The current state of the available data indicates that there is a need for new and complementary experimental information for high-pressure VLE, and pure component properties. This contribution is a continuation of the work reported by López-Porfiri et al., [9] as well as other works available in the literature [8,1012]. However, specific data of the high-pressure VLE for $\mathrm{CO}_{2}$ and (E)-2-hexenal has not been previously reported in the literature. The main goal is to provide physicochemical properties data and modeling required for the development and scale-up of extraction processes, mainly based on packed columns using $\mathrm{SC}-\mathrm{CO}_{2}$ at countercurrent for the recovery of key fruit aroma components.

The specific objective of this work is to contribute with new experimental data $\left(T, p, x_{\mathrm{i}}, y_{\mathrm{i}}\right)$ for the isothermal high-pressure VLE of the binary systems $\mathrm{CO}_{2}(\mathrm{i}=1)+(\mathrm{E})-2$-hexenal $(\mathrm{i}=2)$, as well as experimental data of $\rho_{2}$ and $\eta_{2}$ for pure (E)-2-hexenal. In addition, we model the experimental measurements using the Peng-Robinson equation of state with the van der Waals and Wong-Sandler mixing rules, as well as the Perturbed Chain - Statistical Associating Fluid Theory (PC-SAFT) equation of state.

\section{Materials and Methods}

\subsection{Materials}


(E)-2-Hexenal (99 \% purity. CAS: 6728-26-3) was purchased from Sigma-Aldrich (St. Louis. MO). Carbon dioxide (99.99\% purity) and chromatographic carrier gas helium (99.995\% purity) were purchased from Linde-Chile S.A. Reagents were used without further purification.

\subsection{High-pressure vapor + liquid equilibrium measurements}

The experimental design and procedure used to measure the isothermal high-pressure vapor + liquid equilibria of the binary system $\mathrm{CO}_{2}+(\mathrm{E})$-2-hexenal were previously described in detail by López-Porfiri et al. [9], and Bejarano et al. [11]. The temperatures and pressures measured were up to $333.2 \mathrm{~K}$ and 10 MPa constrained by the equipment limits and data requirements. The apparatus used a static-analytic methodology, where the main component is a high-pressure view-cell (Thar-Tech. Pittsburgh. PA) of $600 \mathrm{~cm}^{3}$, with ports for direct sampling of the vapor and liquid phases.

The experimental procedure started with approximately $100 \mathrm{~cm}^{3}$ of (E)-2-hexenal loaded into the empty and clean cell. It continued with the setting of the selected temperature in the controller (Digi-Sense Vernon Hills, IL), and the purge of the remaining air with $\mathrm{CO}_{2}$ at low-pressure. When the temperature was in steady state, the $\mathrm{CO}_{2}$ was slowly added to the cell with a syringe pump (Teledyne ISCO, 260D, Lincoln, NE) until it reached the previously selected pressure. All the experiments confirmed that after 4 hours of stirring and temperature fluctuations $\leq 0.1 \mathrm{~K}$, the mixture reached the equilibrium condition. The sapphire windows of the cell allowed for the confirmation of the number and type of phases. The molar fraction of the vapor phase was assessed by using an on-line micro-sample injector (ROLSI, Armines, Paris, France) connected to a gas chromatograph (PerkinElmer, Clarus 500, Waltham, MA) to detect $\mathrm{CO}_{2}$ and (E)-2-hexenal. The capillary column selected was a HayeSep C-ValcoPLOT (VICI Metronics, Houston, TX) $30 \mathrm{~m}$ long, $0.53 \mathrm{~mm}$ internal diameter, and $20 \mu \mathrm{m}$ of thickness. The gas carrier used was helium at $10 \mathrm{~cm}^{3} \cdot \mathrm{min}^{-1}$. The temperature of the injector and the thermal conductivity detector was $423 \mathrm{~K}$, and the oven operated at $373 \mathrm{~K}$. The molar fraction of the liquid phase was determined with a micro needle-flow control valve connected to a cold-trap and a wet-test meter. The (E)-2-hexenal 
condensed in the cold-trap was weighted with an analytical balance (RADWAG, North Miami Beach, FL). The volume of $\mathrm{CO}_{2}$ was quantified in the wet-test meter (Ritter, TG05, Germany) at room temperature and atmospheric pressure. The volumetric properties of the $\mathrm{CO}_{2}$ were calculated with the NIST [13] database. Molar fractions reported were, on average, three solubility measurements, with relative standard deviations lower than $5 \%$.

The standard uncertainties of temperature $(\mathrm{u}(T)=0.1 \mathrm{~K})$ and (pressure $\mathrm{u}(p)=0.01 \mathrm{MPa}$ ), as well as the combined expanded uncertainty of the $\mathrm{CO}_{2}(1)$ mole fractions in vapor $\left(\mathrm{U}_{\mathrm{Comb}}\left(y_{1}\right)\right)$ and liquid $\left(\mathrm{U}_{\mathrm{Comb}}\left(x_{1}\right)\right)$ phases were estimated according to the definitions of Chirico et al. [14]. Specifically, $\mathrm{U}_{\mathrm{Comb}}\left(y_{1}\right)$ was estimated using the method proposed by Miller and Miller [15], and $\mathrm{U}_{\mathrm{Comb}}\left(x_{1}\right)$ was calculated from the information available for the experimental methodology and measured data [9]. For both uncertainties, a confidence level of $95.45 \%$ was selected, which meant a coverage factor of $2[9,14]$.

\subsection{Density and dynamic viscosity measurements}

Density and dynamic viscosity were measured for (E)-2-hexenal in an Anton Paar Densitometer (DMA4500M, Austria), with a coupled modular Anton Paar Lovis micro-viscometer (2000ME, Austria) [16]. The densitometer uses a vibrating U-tube to provide density measurements, and according to the procedure, this apparatus was previously calibrated with distilled deionized and degassed water and dry air at a pressure of $101.3 \mathrm{kPa}$. The standard uncertainty reported for the manufacturer is $\mathrm{u}(\rho)=0.05 \mathrm{~kg} \cdot \mathrm{m}^{-}$

3. The dynamic viscosity measurements are based on the falling ball principle. The micro-viscometer was calibrated using viscosity standards provided by the manufacturer. The viscosity measurements have a reported relative standard deviation of $0.4 \%$, with a standard uncertainty of $\mathrm{u}(\eta)=0.02 \mathrm{mPa} \cdot \mathrm{s}$.

\subsection{Thermodynamic of phase equilibria modeling}

The vapor + liquid equilibrium was modeled using the $\phi-\phi$ approach, Eq. (1) [17], following the methodology utilized by López-Porfiri et al. [9].

$y_{\mathrm{i}} \cdot \bar{\phi}_{\mathrm{i}}^{\mathrm{V}}=x_{\mathrm{i}} \cdot \bar{\phi}_{\mathrm{i}}^{\mathrm{L}}$ 
The fugacity coefficients of the vapor phase $\left(\bar{\phi}_{\mathrm{i}}^{\mathrm{V}}\right)$ and liquid phase $\left(\bar{\phi}_{\mathrm{i}}^{\mathrm{L}}\right)$ were calculated using two different equations of state, Peng-Robinson (PR) equation of state (EoS) [17], and PC-SAFT [18,19].

For the PR-EoS, two mixing rules were selected. The classical quadratic van der Waals (vdW) mixing rule with two adjustable interaction parameters, $\mathrm{k}_{12}$ and $\mathrm{l}_{12}$, and the Wong and Sandler (WS) mixing rule including the Non-Random Two Liquid model (NRTL) for the calculation of the excess Gibbs free energy [20], with four binary interaction coefficients $\left(\mathrm{k}_{12} . \alpha_{12} . \tau_{12} . \tau_{21}\right)$.

For PC-SAFT, the $\mathrm{CO}_{2}(1)$ was considered as a non-polar molecule and the (E)-2-hexenal (2) as a dipolar and non-associating molecule. In this work, the perturbation expansion of the Helmholtz residual energy included the terms hard-chain, dispersion, and dipolar contribution [21]. The four pure-component parameters, number of segments $\left(\mathrm{m}_{2}\right)$, segment diameter $\left(\sigma_{2}\right)$, dispersion energy $\left(\varepsilon_{2} / \mathrm{k}_{2}\right)$, and the fraction of dipolar segments in the molecule $\left(\mathrm{x}_{\mathrm{p}, 2}\right)$, were adjusted from the density and vapor pressure data of $(\mathrm{E})$ 2-hexenal by fixing its experimental dipole moment $\left(\mu_{2}\right)$. This value was obtained from the literature for 1-hexanal [22], which is molecularly comparable to (E)-2-hexenal. The three parameters, $\mathrm{m}_{1}, \sigma_{1}$ and $\varepsilon_{1} / \mathrm{k}_{1}$, for $\mathrm{CO}_{2}$ were obtained from the literature [18]. The Lorentz-Bertherlot mixing rules [18], Eq. (2), were used to calculate the combined segment diameter $\left(\sigma_{12}\right)$ and the combined dispersion energy $\left(\varepsilon_{12}\right)$ of the mixtures, with one adjusting binary interaction coefficient, $\mathrm{k}_{12}$.

$$
\begin{aligned}
& \sigma_{12}=\frac{1}{2}\left(\sigma_{1}+\sigma_{2}\right) \\
& \varepsilon_{12}=\sqrt{\varepsilon_{1} \varepsilon_{2}}\left(1-\mathrm{k}_{12}\right)
\end{aligned}
$$

\section{Results and Discussion}

\subsection{Experimental high-pressure vapor + liquid equilibria data}

Table 1 reports the isothermal VLE data measured for the system $\mathrm{CO}_{2}+(\mathrm{E})$-2-hexenal at (313.2. 323.2 and 333.2) $\mathrm{K}$, and pressures from (2.2 to 9.8) $\mathrm{MPa}$. This data was analyzed and validated according to 
the methodology proposed by López-Porfiri et al. [9], which considered the thermodynamic consistency evaluation, as well as the estimation of the uncertainties. For each isothermal dataset, the experimental mole fractions of the vapor phase were compared with the values estimated by using the Gibbs-Duhem equation to define the thermodynamic consistency. The estimations were performed using the tools available in Aspen Plus v.9 (ApenTech. Bedford. MA) based on the modification of Fredenslund [23]. Table 2 indicates that the isotherms of (313.2 and 333.2) K were thermodynamically consistent. Both isotherms verified that the mean absolute deviations between experimental and estimated molar fractions were lower than the recommended upper limit of $0.01 \mathrm{~mol} \cdot \mathrm{mol}^{-1}[23]$. For the isotherm of $323.2 \mathrm{~K}$, even though the mean absolute deviations exceed the limit of $2 \%$, this divergency was considered negligible and the isotherm is considered as thermodynamically consistent. In Table 1, the values of the estimated uncertainties, showing that $\mathrm{U}_{\mathrm{Comb}}\left(y_{1}\right) \leq 0.045 \mathrm{~mol} \cdot \mathrm{mol}^{-1}$ and $\mathrm{U}_{\mathrm{Comb}}\left(x_{1}\right) \leq 0.016 \mathrm{~mol} \cdot \mathrm{mol}^{-1}$, are shown. In addition, no significant differences were found in the numerical values of the uncertainties between the three isotherms measured.

The experimental information listed in Table 1 was included in Figure 2 and corresponds to the equilibrium between the vapor and liquid phases, without visually detecting any partial immiscibility. The phase envelopes for the three isotherms measured were similar, and their shape can be attributed to the significant differences in the relative volatility of $\mathrm{CO}_{2}$ and (E)-2-hexenal. The phase envelopes presented a critical pressure at $\mathrm{CO}_{2}$ molar fractions higher than $95 \%$. The pressures corresponding to the critical solution points increased with the temperature and were estimated $<1.1 \mathrm{MPa}$. No references were found in the literature with information of the VLE for the system $\mathrm{CO}_{2}+(\mathrm{E})$-2-hexenal, nevertheless the phase behavior is comparable to other key apple aroma components studied, for instance, $\mathrm{CO}_{2}+$ hexanal $[9,24]$ and $\mathrm{CO}_{2}+$ ethyl-2-methylbutyrate [9].

\subsection{Density and dynamic viscosity of pure (E)-2-hexenal}


Experimental density and dynamic viscosity of pure (E)-2-hexenal measured at $101.13 \mathrm{kPa}$, and temperatures from (293.2 to 353.2) $\mathrm{K}$ are reported in Table 3. Both properties decreased with temperature, and the values ranged from $(797.45$ to 851.87$) \mathrm{kg} \cdot \mathrm{m}^{-3}$ for density, and from $(0.469$ to 0.934$)$ $\mathrm{mPa} \cdot \mathrm{s}$ for viscosity. The (open) literature reports at $293 \mathrm{~K}$ a density value with a deviation of $0.39 \%$ [25] from the data measured in this work. Data measured for the dynamic viscosity for pure (E)-2-hexenal was not found in the literature.

Experimental data measured were calculated with PC-SAFT, with a deviation of $\pm 21.1 \mathrm{~kg} \cdot \mathrm{m}^{-3}$ for the density. The dynamic viscosity was correlated to the temperature using the Vogel-Fulcher-Tamman (VFT) model [26]. The Eq. (3) reports the vales of the adjusted parameters, with a deviation of \pm 0.002 $\mathrm{mPa} \cdot \mathrm{s}$.

$\eta_{2}(\mathrm{mPa} \cdot \mathrm{s})=0.0416 \cdot \exp \left(\frac{662.7}{T(\mathrm{~K})-80.23}\right)$

\subsection{Thermodynamic modeling of high-pressure vapor + liquid equilibrium data}

\subsubsection{Peng-Robinson equation of state}

Table 4 reports the properties of pure components for $\mathrm{CO}_{2}(1)$ and (E)-2-hexenal (2) obtained from the NIST Standard Database v5.0 [13], except for the acentric factor of the (E)-2-hexenal that was estimated with the Lee-Kesler correlation [27]. The critical temperature and pressure, as well as boiling temperature for (E)-2-hexenal, were estimated with the Joback group contribution method [27]. The interaction parameters of the mixing rules were estimated according to López-Porfiri et al., [9] by minimizing the relative root-mean square deviation, $\delta\left(y_{1}, x_{1}\right)$, defined by the Eq. (4) [14].

$$
\delta\left(y_{1}, x_{1}\right)=\sqrt{\frac{1}{\mathrm{~N}} \sum_{\mathrm{j}=1}^{\mathrm{N}}\left[\delta\left(y_{1}\right)_{\mathrm{j}}^{2}+\delta\left(x_{1}\right)_{\mathrm{j}}^{2}\right]}
$$


Where $\mathrm{N}$ is the total number of experimental data points, $\delta\left(\xi_{1}\right)_{\mathrm{j}}=\left(\xi_{1}^{\text {Calc }}-\xi_{1}\right)_{\mathrm{j}} / \xi_{1, \mathrm{j}}$ represents the individual relative deviation for the molar fraction of $\mathrm{CO}_{2}(1)$ between calculated $\left(\xi_{1 . j}^{\text {Calc }}\right)$ and measured $\left(\xi_{1, \mathrm{j}}\right)$ values for each phase $\left(\xi_{1}=x_{1}, y_{1}\right)$, and for each data point $(\mathrm{j})$.

Table 5 reports the interaction parameters and deviations obtained for each mixing rule and isotherm. These results showed that when the PR-EoS combined with WS + NRTL mixing rule, with a relative root-mean square deviation of $\delta\left(y_{1}, x_{1}\right) \leq 1.83 \%$, it had a better performance compared with the two options considered for $\mathrm{vdW}$ mixing rule. With $\mathrm{k}_{12} \neq 0$ and $\mathrm{l}_{12} \neq 0$, the deviations were $\delta\left(y_{1}, x_{1}\right) \leq 17.33 \%$, on the other hand, with $\mathrm{k}_{12} \neq 0$ and $1_{12}=0$ the values for the deviations were reduced to $\delta\left(y_{1}, x_{1}\right) \leq 17.33 \% 7.95 \%$. An over-fitting problem could explain the improvement of the $\mathrm{vdW}$ mixing rule when it was used with three adjusted parameters, $\mathrm{k}_{12} \neq 0$ and $\mathrm{l}_{12}=0$, instead of six parameters, $\mathrm{k}_{12} \neq 0$ and $\mathrm{l}_{12} \neq 0$. The higher deviations were detected for the liquid phase with $\delta\left(x_{1}\right) \leq 17.32 \% 7.95 \%$ for vdW with $\mathrm{k}_{12} \neq 0$ and $\mathrm{l}_{12}=0$, and $\delta\left(x_{1}\right) \leq 1.82 \%$ for WS+NRTL. These values can be explained considering the theoretical nature of the WS + NRTL mixing rule, which is able to take into account the nonidealities of the liquid phase. On the other hand, the vdW mixing rule considers weaker interactions associated to the van der Waals forces. For the vapor phase, there were no significant differences in the deviations for $\mathrm{vdW}$ with $\mathrm{k}_{12} \neq 0$ and $\mathrm{l}_{12}=0, \delta\left(y_{1}\right) \leq 0.88 \% 0.89 \%$, compared with WS + NRTL, $\delta\left(y_{1}\right) \leq 0.87 \%$.

The results of the modeling using the PR-EoS have been included in Figure 2, considering for vdW mixing rule the option with $\mathrm{k}_{12} \neq 0$ and $\mathrm{l}_{12}=0$. With both mixing rules, vdW and WS $+\mathrm{NRTL}$, the PREoS was able to represent the phase envelope (not shown in Figure 2) and to detect the critical pressures, estimated for a $\mathrm{CO}_{2}$ content $>95 \% \mathrm{~mol} \cdot \mathrm{mol}^{-1}$. It was verified that the value of the critical pressures 
increased with the temperature for both mixing rules. In particular, for WS+NRTL the value of these pressures increased with the temperature from approximately $8.5 \mathrm{MPa}$ at $313.2 \mathrm{~K}$ to $1.1 \mathrm{MPa}$ at $333.2 \mathrm{~K}$.

\subsubsection{Perturbed Chain - Statistical Associating Fluid Theory equation of state}

Table 6 reports the pure-component parameters used to model the VLE data measured. For $\mathrm{CO}_{2}(1)$, these parameters were obtained from Gross and Sadowski [18] and used without further modifications. For (E)-2-hexenal (2), the parameters were adjusted from the density data measured in this work, and the vapor pressure data reported by Meneses et al. [10]. The relative root-mean square deviations between the experimental and calculated values were $0.23 \%$ for density, and $0.61 \%$ for vapor pressure. $\mathrm{The}_{2}$ was considered a non-polar molecule, neglecting its quadrupolar moment contribution [28]. The (E)-2hexenal was assumed as a non-associating molecule with dipole-dipole interactions, in a similar approach used by Dominik et al. [21] to model ketones.

The modeling of the high-pressure VLE using the PC-SAFT considered two alternatives. First, the use of only the pure-component information as a predictive tool $\left(\mathrm{k}_{12}=0\right)$, and second, adjusting the binary interaction coefficient to the experimental data $\left(\mathrm{k}_{12} \neq 0\right)$, as a correlation tool. Table 7 reports the relative root-mean square deviations calculated for the molar fraction of the vapor and liquid with both approaches. The results confirmed that the predictive option presented higher deviations, $\delta\left(y_{1}, x_{1}\right)=44.76 \%$, compared to the correlation with a value of $\mathrm{k}_{12}=0.0752, \delta\left(y_{1}, x_{1}\right)=9.80 \%$. The major differences were observed for the molar fraction of the liquid phase with $\delta\left(x_{1}\right)=44.75 \%$ for the prediction, against $\delta\left(x_{1}\right)=9.78 \%$ for the correlation. For the vapor phase, both options resulted in comparable deviations, $\delta\left(y_{1}\right)=0.64 \%$ for the prediction, and $\delta\left(y_{1}\right)=0.61 \%$ for the correlation.

The numerical modeling results can be confirmed in Figure 3 where the experimental information and the calculations with PC-SAFT were plotted. This equation has the capability of predicting the phase envelope, including the existence of a critical pressure for each isotherm at high $\mathrm{CO}_{2}$ molar fractions. 
Moreover, the prediction and correlation of the molar fraction of the vapor phase were higher than the measured values. For the liquid phase, the molar fractions predicted were lower than the experimental, and the correlated molar fractions were higher.

The PR-EoS combined with WS + NRTL mixing rule showed a higher capability of correlating the experimental VLE data than the PC-SAFT EoS. The examination of the relative root-mean square deviations indicated a reduction of $81 \%$ for PR-EoS compared with PC-SAFT. Also, there was a significant disparity in the modeling of the molar fraction of the vapor phase, exhibiting the PR-EoS a reduction of $42 \%$ in the relative deviations regarding to PC-SAFT. The justification is based on the number of adjustable binary interaction coefficients. For the PR-EoS with WS+NRTL, the four coefficients $\left(\mathrm{k}_{12}, \alpha_{12}, \tau_{12}, \tau_{21}\right)$ were fixed individually for each isotherm, resulting in a total of twelve parameters. This number decreases significantly to one coefficient $\left(\mathrm{k}_{12}\right)$ for the PC-SAFT. The values corresponding to the critical pressures estimated for the three isotherms measured were similar for both equations. The open phase envelopes around the critical point obtained with PC-SAFT showed in Figure 3 was as a consequence of the methodology implemented (algorithm) to reproduce specifically the experimental data measured. This made it possible to compare the PC-SAFT capabilities of correlation and prediction. Nevertheless, the PC-SAFT has proved to be able to represent the critical point of mixtures [19]. The results described in this work, data and calculations of the molar fraction and the phase envelopes, are relevant to being able to evaluate a process to recover the key aroma components, like (E)-2-hexenal, from liquid mixtures using $\mathrm{SC}-\mathrm{CO}_{2}$ as a solvent in a countercurrent in a packed column.

\section{Conclusions}

The isothermal vapor + liquid equilibrium of $\mathrm{CO}_{2}+(\mathrm{E})$-2-hexenal was measured at (313.2. 323.2 and 333.2) $\mathrm{K}$ and pressure lower than $9.8 \mathrm{MPa}$. The experimental data was validated by a procedure that allowed to verify the thermodynamic consistency, as well as to estimate the combined expanded 
uncertainties. Results showed that the uncertainties estimated for the $\mathrm{CO}_{2}$ mole fractions were $\leq 0.045$ $\mathrm{mol} \cdot \mathrm{mol}^{-1}$ (vapor) and $\leq 0.016 \mathrm{~mol} \cdot \mathrm{mol}^{-1}$ (liquid). The isothermal phase envelopes measured presented a critical pressure at carbon dioxide molar fractions $\geq 95 \% \mathrm{~mol} \cdot \mathrm{mol}^{-1}$. The pressure corresponding to the critical point increased with temperature, and the values were estimated lower than 1.1 MPa. The density and dynamic viscosity of pure (E)-2-hexenal were measured at $101.13 \mathrm{kPa}$ and temperatures from (292.2 to 353.2$) \mathrm{K}$, with values ranged from $(797.45$ to 851.87$) \mathrm{kg} \cdot \mathrm{m}^{-3}$ for density, and from $(0.469$ to 0.934) $\mathrm{mP} \cdot \mathrm{s}$ for viscosity. The Peng-Robinson and the Perturbed Chain - Statistical Associating Fluid Theory were the two equations of state selected to model the vapor + liquid equilibria. Both equations were able to represent the phase envelopes. For the Peng-Robinson, two mixing rules were used, the van der Waals classical quadratic and the Wong-Sandler with the Non-Random Two Liquid model. The relative root-mean square deviation calculated simultaneously for the $\mathrm{CO}_{2}$ molar fractions of vapor and liquid phases using the two mixing rules were, $17.33 \%$ and $1.83 \%$, respectively. The Perturbed Chain Statistical Associating Fluid Theory predicted the mole fractions with a deviation of $44.76 \%$. This value was reduced to $9.80 \%$ when an adjustable binary interaction coefficient was included. According to these results, this last equation would be recommended for the development and scale-up of processes for the recovery of key fruit aroma components.

\section{Acknowledgements}

This work was funded by the Chilean agency Fondecyt (Regular Project 115-0822), and by the Incentive Program for Scientific Initiation from the Universidad Técnica Federico Santa María. The authors wish to thank Ana I. González in particular; her help is greatly appreciated.

\section{References}

[1] C. Sanz, J.M. Olias, A.G. Perez, in: F.A. Tomas-Barberan, R.J. Robins (Eds.), Phytochem. Fruit Veg., Oxford Universty Press Inc., New York, USA, 1997, 125-155.

[2] J. Dixon. E.W. Hewett. New Zeal. J. Crop Hortic. Sci. 28 (2000) 155-173. 
[3] M. Czerny. M. Christlbauer. M. Christlbauer. A. Fischer. M. Granvogl. M. Hammer. C. Hartl. N.M. Hernandez. P. Schieberle. Eur. Food Res. Technol. 228 (2008) 265-273.

[4] M.P. Nikfardjam, D. Maier, Food Chem. 126 (2011) 1926-1933.

[5] J. Koch, in: Kongress-Bericht XIV Int. Fruchtsaft-Kongress, Meran, 1976, 18-21.

[5] W.G. Schultz. J. M. Randall. Food Tech. 24 (1970). 94-98.

[6] M. Mukhopaday, Natural Extracts Using Supercritical Carbon Dioxide, CRC Press, Florida, Fl, 2000.

[7] G. Brunner. Gas Extraction. An Introduction to Fundamentals of Supercritical Fluids and the Application to Separation Processes. Springer. New York. NY. 1994.

[8] A. Bejarano, P.C. Simões, J.M. del Valle, J. Supercrit. Fluids 107 (2016) 321-348.

[9] P. López-Porfiri, R. Villablanca-Ahues, A. Bejarano, J.C. de la Fuente, J. Chem. Thermodyn. 115 (2017), 269-275.

[10] D.A. Meneses, A. Bejarano, J.C. de la Fuente, J. Chem. Thermodyn. 74 (2014) 16-21.

[11] A. Bejarano, P.I. López, J.M. del Valle, J.C. de la Fuente, J. Chem. Thermodyn. 89 (2015) 79-88.

[12] A. Bejarano, J.M. del Valle, J. Supercrit. Fluids 120 (2017) 266-274.

[13] NIST, Fluid Thermodynamics and Transport Properties. Version 5.0 (http//www.nist.gov/srd/nist23.htm).

[14] R.D. Chirico. M. Frenkel. V.V. Diky. K.N. Marsh. R.C. Wilhoit. J. Chem. Eng. Data. 48 (2003) 1344-1359.

[15] J.N. Miller, J.C. Miller, Statistics and chemometrics for analytical chemistry, Prentice Hall, Gosport, UK, 2010.

[16] N.F. Gajardo-Parra, M.J. Lubben, J.M. Winnert, A. Leiva, J.F. Brennecke, R.I. Canales, J. Chem. Thermodyn. 133(2019) 272-284.

[17] S.M. Walas. Phase Equilibria in Chemical Engineering; Butterworth Publisher: Boston. MA. 1985.

[18] J. Gross, G. Sadowski, Ind. Eng. Chem. Res. 40 (2001) 1244-1260. 
[19] J. Gross and G. Sadowski, Ind. Eng. Chem. Res. 41 (2002) 5510-5515.

[20] D.S. Wong, S.I. Sandler, AIChE J. 38 (1992) 671-680.

[21] A. Dominik, W.G. Chapman, M. Kleiner, G. Sadowski, Ind. Eng. Chem. Res. 44 (2005) 69286938.

[22] C.L. Yaws and P.K. Narasimham, Chapter 19. Dipole moment-Organic compounds, From: Thermophysical Properties of Chemicals and Hydrocarbons, Retrieved from https://app.knovel.com/hotlink/itble/rcid:kpYTPCHE02/id:kt00780033/yaws-thermophysicalproperties/dipole-moments-organic

[23] A. Fredenslund. Vapor-Liquid Equilibria Using UNIFAC. Elsevier. 1977.

[24] D. Seredynska. G. Ullrich. G. Wiegand. N. Dahmen. and E. Dinjus, J. Chem. Eng. Data 52 (2007) 2284-2287.

[25] M. Karelson, A. Perkson, Computers and Chemistry 23 (1999) 49-59.

[26] H. Vogel, Phy. Z. 22 (1921) 645-646.

[2726] B.E. Poling. J.M. Prausnitz. J.P. O'Connell. The Properties of Gases and Liquids. fifth ed.. Mc Graw Hill. New York. NY. 2001.

[2827] R.I. Canales, C. Held, M.J. Lubben, J.F. Brennecke, G, Sadowski, Ind. Eng. Chem. Res. 56 (2017) 9885-9894. 
Table 1. Experimental temperature $(T)$, pressure $(p)$, molar fraction of liquid $\left(x_{1}\right)$ and vapor $\left(y_{1}\right)$ phases, and its combined expanded uncertainty $\left(\mathrm{U}_{\mathrm{Comb}}\left(x_{1}\right), \mathrm{U}_{\mathrm{Comb}}\left(y_{1}\right)\right)$, for the binary system $\mathrm{CO}_{2}(1)+(\mathrm{E})-2-$ hexenal (2).

\begin{tabular}{|c|c|c|c|c|c|}
\hline$T^{(\mathrm{a})} / \mathrm{K}$ & $p^{(\mathrm{b})} / \mathrm{MPa}$ & $x_{1} / \mathrm{mol} \cdot \mathrm{mol}^{-1}$ & $\mathrm{U}_{\mathrm{Comb}}\left(x_{1}\right)^{(\mathrm{c})} / \mathrm{mol} \cdot \mathrm{mol}^{-1}$ & $y_{1} / \mathrm{mol} \cdot \mathrm{mol}^{-1}$ & $\mathrm{U}_{\mathrm{Comb}}\left(y_{1}\right)^{(\mathrm{c})} / \mathrm{mol} \cdot \mathrm{mol}^{-1}$ \\
\hline \multicolumn{6}{|c|}{$\mathrm{CO}_{2}(1)+(\mathrm{E})-2$-hexenal (2) } \\
\hline \multirow[t]{7}{*}{313.2} & 2.46 & 0.207 & 0.009 & 0.991 & 0.014 \\
\hline & 3.72 & 0.342 & 0.014 & 0.996 & 0.005 \\
\hline & 5.07 & 0.455 & 0.014 & 0.996 & 0.004 \\
\hline & 6.18 & 0.556 & 0.015 & 0.997 & 0.002 \\
\hline & 7.01 & 0.601 & 0.014 & 0.997 & 0.003 \\
\hline & 8.16 & 0.684 & 0.013 & 0.996 & 0.002 \\
\hline & 9.82 & 0.809 & 0.016 & 0.994 & 0.002 \\
\hline \multirow[t]{7}{*}{323.2} & 2.16 & 0.188 & 0.005 & 0.975 & 0.044 \\
\hline & 3.28 & 0.311 & 0.004 & 0.996 & 0.007 \\
\hline & 4.17 & 0.407 & 0.003 & 0.997 & 0.004 \\
\hline & 5.21 & 0.503 & 0.002 & 0.997 & 0.003 \\
\hline & 6.59 & 0.630 & 0.002 & 0.997 & 0.002 \\
\hline & 7.46 & 0.725 & 0.001 & 0.997 & 0.002 \\
\hline & 8.92 & 0.860 & 0.001 & 0.996 & 0.002 \\
\hline \multirow[t]{6}{*}{333.2} & 3.03 & 0.326 & 0.008 & 0.993 & 0.010 \\
\hline & 4.12 & 0.496 & 0.011 & 0.989 & 0.011 \\
\hline & 5.10 & 0.598 & 0.012 & 0.998 & 0.003 \\
\hline & 6.39 & 0.734 & 0.014 & 0.998 & 0.002 \\
\hline & 7.03 & 0.814 & 0.014 & 0.998 & 0.002 \\
\hline & 8.04 & 0.939 & 0.015 & 0.997 & 0.002 \\
\hline
\end{tabular}

${ }^{(a)}$ Standard uncertainty for temperature, $\mathrm{u}(T)=0.1 \mathrm{~K}$.

(b) Standard uncertainty for pressure, $\mathrm{u}(p)=0.05 \mathrm{MPa}$.

${ }^{(c)}$ Values estimated with a 0.9545 level of confidence [14] for combined expanded uncertainty of molar fraction of $\mathrm{CO}_{2}$

(1) in the liquid phase, $\mathrm{U}_{\mathrm{Comb}}\left(x_{1}\right)$, and vapor phase, $\mathrm{U}_{\mathrm{Comb}}\left(y_{1}\right)$. 
Table 2. Thermodynamic consistency evaluation of the experimental data measured, based on the point test of van Ness, modified by Fredenslund [23].

\begin{tabular}{lcc}
\hline & \multicolumn{2}{c}{$\mathrm{CO}_{2}(1)+(\mathrm{E})-2$-hexenal $(2)$} \\
\hline 313.2 & Mean absolute deviation & Evaluation \\
323.2 & 0.0063 & Consistent $^{(\mathrm{a}}$ \\
333.2 & 0.0107 & Consistent $^{(\mathrm{a}}$ \\
\hline
\end{tabular}

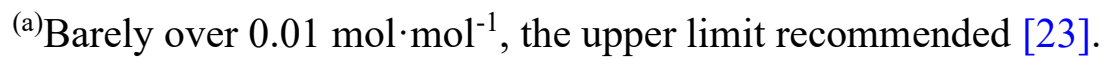


Table 3. Experimental temperature $(T)$, density $\left(\rho_{2}\right)$, and dynamic viscosity $\left(\eta_{2}\right)$ of pure (E)-2-hexenal (2) at $101.13 \mathrm{kPa}$. The standard uncertainties (u) reported correspond to information from the manufacturer [16].

\begin{tabular}{ccc}
\hline$T^{(\mathrm{a})} / \mathrm{K}$ & $\rho_{2}{ }^{(\mathrm{b})} / \mathrm{kg} \cdot \mathrm{m}^{-3}$ & $\eta_{2}{ }^{(\mathrm{c})} / \mathrm{mPa} \cdot \mathrm{s}$ \\
\hline 293.2 & 851.9 & 0.93 \\
298.2 & 847.5 & 0.87 \\
303.2 & 843.1 & 0.81 \\
308.2 & 838.6 & 0.76 \\
313.2 & 834.1 & 0.72 \\
318.2 & 829.7 & 0.67 \\
323.2 & 825.1 & 0.64 \\
328.2 & 820.6 & 0.60 \\
333.2 & 816.1 & 0.57 \\
338.2 & 811.5 & 0.54 \\
343.2 & 806.8 & 0.52 \\
348.2 & 802.2 & 0.49 \\
353.2 & 797.5 & 0.47 \\
\hline
\end{tabular}

${ }^{(a)}$ Standard uncertainty for temperature, $\mathrm{u}(T)=0.1 \mathrm{~K}$

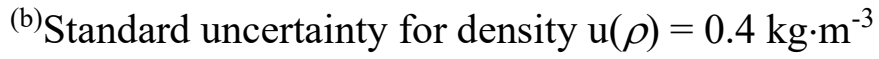

${ }^{(c)}$ Standard uncertainty for dynamic viscosity $\mathrm{u}(\eta)=0.02 \mathrm{mPa} \cdot \mathrm{s}$ 
Table 4. Pure component properties for $\mathrm{CO}_{2}(1)$ and (E)-2-hexenal (2), from literature or estimated in this work.

\begin{tabular}{lcccccc}
\hline \multirow{2}{*}{ Property } & \multicolumn{2}{c}{$\mathrm{CO}_{2}(1)$} & \multicolumn{2}{c}{ (E)-2-hexenal (2) } \\
\cline { 2 - 7 } & Value & $\begin{array}{c}\text { Source } \\
\text { (Estimation Method) }\end{array}$ & Value & $\begin{array}{c}\text { Source } \\
\text { (Estimation Method) }\end{array}$ \\
\hline Molecular weight (Da) & 44.01 & NIST & {$[13]$} & 98.14 & Joback & {$[2726]$} \\
Critical temperature (K) & 304.2 & NIST & 625.0 & Joback & \\
Critical pressure (MPa) & 7.38 & NIST & 3.24 & Joback \\
Acentric factor (-) & 0.225 & NIST & 0.321 & Lee-Kesler & {$[2726]$} \\
\hline
\end{tabular}


Table 5. Optimal values of parameters for the Peng-Robinson equation of state with two mixing rules, van der Waals ( $\mathrm{k}_{1 \mathrm{i}}$. $\left.1_{1 \mathrm{i}}\right)$ and $\mathrm{Wong}$ Sandler $\left(\mathrm{k}_{1 \mathrm{i}}\right)$ plus Non-Random Two Liquid (NRTL) model $\left(\alpha_{1 \mathrm{i}} \cdot \tau_{1 \mathrm{i}} . \tau_{\mathrm{i} 1}\right)$ used to model the vapor + liquid equilibria of CO $2(1)+(\mathrm{E})-2-\mathrm{hexenal}$ (2).

\begin{tabular}{|c|c|c|c|c|c|c|c|c|c|c|c|c|}
\hline \multirow[b]{2}{*}{$\mathrm{T} / \mathrm{K}$} & \multicolumn{5}{|c|}{ Peng-Robinson + van der Waals } & \multicolumn{7}{|c|}{ Peng-Robinson + (Wong-Sandler + NRTL) } \\
\hline & $\mathrm{k}_{12}$ & $1_{12}$ & $100 \cdot \delta\left(y_{1}, x_{1}\right) / \%$ & $100 \cdot \delta\left(x_{1}\right) / \%$ & $100 \cdot \delta\left(y_{1}\right) / \%$ & $\mathrm{k}_{12}$ & $\alpha_{12}$ & $\tau_{12}$ & $\tau_{21}$ & $\begin{array}{c}100 \cdot \delta\left(y_{1}, x_{1}\right) / \\
\%\end{array}$ & $100 \cdot \delta\left(x_{1}\right) / \%$ & $100 \cdot \delta\left(y_{1}\right) / \%$ \\
\hline 313.2 & 0.0689 & 0 & 6.32 & 6.30 & 0.47 & 0.6260 & 0.3043 & 0.1941 & 0.9348 & 1.77 & 1.70 & 0.47 \\
\hline 323.2 & -0.0051 & 0 & 7.95 & 7.90 & 0.89 & 0.6267 & 0.47 & 0.7324 & 0.2967 & 1.70 & 1.46 & 0.87 \\
\hline 333.2 & 0.0590 & 0 & 7.51 & 7.51 & 0.26 & 0.6373 & 0.4124 & 0.0053 & 0.7883 & 1.83 & 1.82 & 0.19 \\
\hline 313.2 & 0.0689 & 0.0626 & 17.33 & 17.32 & 0.49 & & & & & & & \\
\hline 323.2 & -0.0051 & -0.0862 & 10.50 & 10.46 & 0.88 & & & & & & & \\
\hline 333.2 & 0.0590 & 0.0009 & 6.33 & 6.32 & 0.31 & & & & & & & \\
\hline
\end{tabular}

$\delta\left(\xi_{1}\right)_{\mathrm{j}}=\left(\xi_{1}^{\text {Calc }}-\xi_{1}\right)_{\mathrm{j}} / \xi_{1, \mathrm{j}}:$ Individual (j) relative deviations between the calculated $\left(\xi_{1, \mathrm{j}}^{\text {Calc }}\right)$ and measured $\left(\xi_{1, \mathrm{j}}\right)$ values of molar fractions of $\mathrm{CO}_{2}(1)$ in liquid phase $\left(\xi_{1}=x_{1}\right)$ or vapor phase $\left(\xi_{1}=y_{1}\right)$.

$\delta\left(y_{1}, x_{1}\right)=\sqrt{\frac{1}{\mathrm{~N}} \sum_{\mathrm{j}=1}^{\mathrm{N}}\left[\delta\left(y_{1}\right)_{\mathrm{j}}^{2}+\delta\left(x_{1}\right)_{\mathrm{j}}^{2}\right]}:$ Relative root-mean square deviation, the objective function used to fit the interaction parameters. 
Table 6. Optimal values of pure-component parameters $\left(\mathrm{m}_{\mathrm{i}}, \sigma_{\mathrm{i}}, \varepsilon_{\mathrm{i}} / \mathrm{k}_{\mathrm{i}}, \mathrm{x}_{\mathrm{p}, \mathrm{i}}, \mu_{\mathrm{i}}\right)$ for the Perturbed Chain - Statistical Associating Fluid Theory equation of state used to model the vapor + liquid equilibria of $\mathrm{CO}_{2}(1)+(\mathrm{E})-2$-hexenal (2).

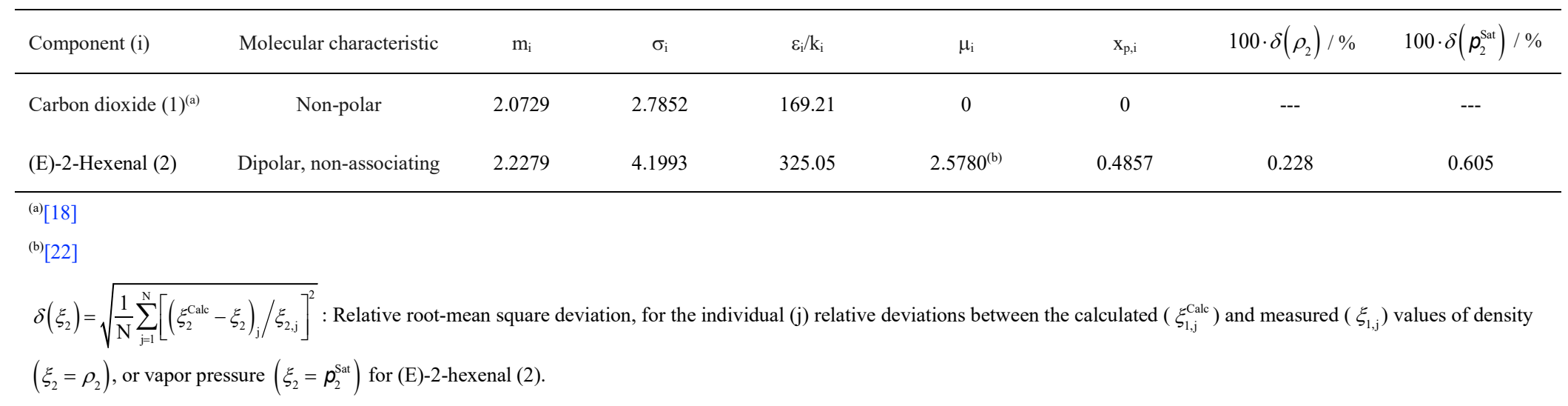


Table 7. Optimal values of parameters for the Perturbed Chain - Statistical Associating Fluid Theory equation of state used as a predictive tool $\left(\mathrm{k}_{12}=0\right)$, and as a correlation tool $\left(\mathrm{k}_{12} \neq 0\right)$ to model the vapor + liquid equilibria of $\mathrm{CO}_{2}(1)+(\mathrm{E})-2$-hexenal $(2)$.

\begin{tabular}{|c|c|c|c|c|c|c|c|c|}
\hline \multirow[b]{2}{*}{$\mathrm{T} / \mathrm{K}$} & \multicolumn{4}{|c|}{ Prediction } & \multicolumn{4}{|c|}{ Correlation } \\
\hline & $\mathrm{k}_{12}$ & $100 \cdot \delta\left(y_{1}, x_{1}\right) / \%$ & $100 \cdot \delta\left(x_{1}\right) / \%$ & $100 \cdot \delta\left(y_{1}\right) / \%$ & $\mathrm{k}_{12}$ & $\begin{array}{c}100 \cdot \delta\left(y_{1}, x_{1}\right) / \\
\%\end{array}$ & $100 \cdot \delta\left(x_{1}\right) / \%$ & $100 \cdot \delta\left(y_{1}\right) / \%$ \\
\hline \multicolumn{9}{|c|}{$313.2]$} \\
\hline 323.2 & 0 & 44.76 & 44.75 & 0.64 & 0.0752 & 9.80 & 9.78 & 0.61 \\
\hline 333.2 & & & & & & & & \\
\hline \multicolumn{9}{|c|}{$\begin{array}{l}\delta\left(\xi_{1}\right)_{\mathrm{j}}=\left(\xi_{1}^{\text {Calc }}-\xi_{1}\right)_{\mathrm{j}} / \xi_{1, \mathrm{j}} \text { Individual }(\mathrm{j}) \text { relative deviations between the calculated }\left(\xi_{1, \mathrm{j}}^{\text {Calc }}\right) \text { and measured }\left(\xi_{1, \mathrm{j}}\right) \text { values of molar fractions of } \mathrm{CO}_{2}(1) \text { in liquid } \\
\text { phase }\left(\xi_{1}=x_{1}\right) \text { or vapor phase }\left(\xi_{1}=y_{1}\right) .\end{array}$} \\
\hline
\end{tabular}




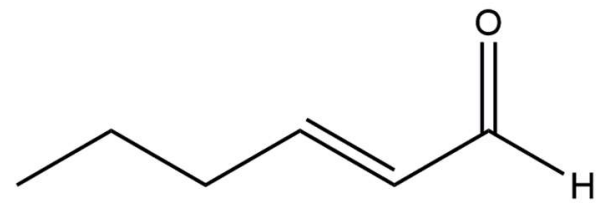

Figure 1. Chemical structure of (E)-2-hexenal. 


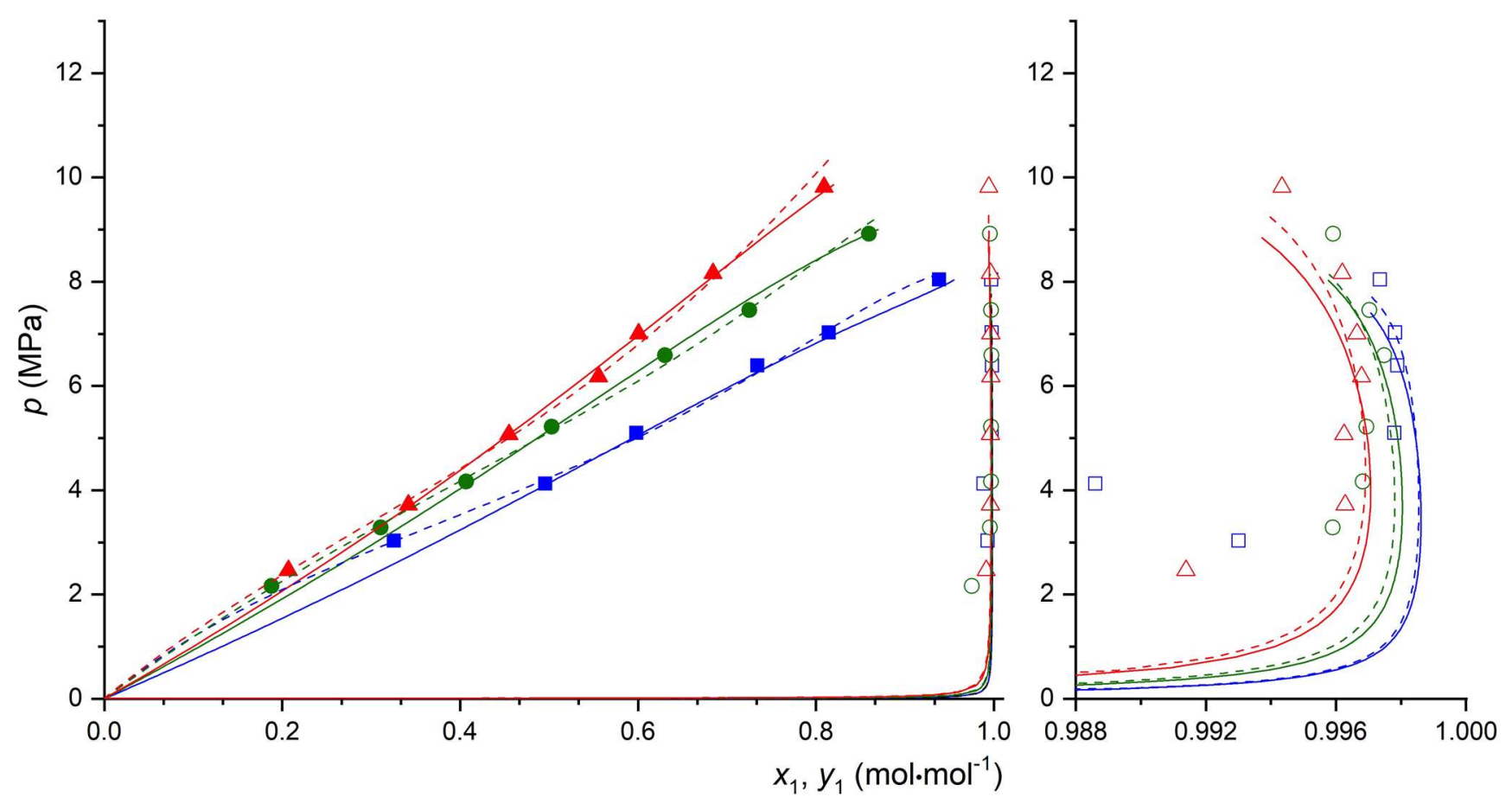

Figure 2. Isothermal vapor + liquid equilibria for the binary system $\mathrm{CO}_{2}(1)+(\mathrm{E})$-2-hexenal (2) at temperatures of $313.2 \mathrm{~K}:(\square, \square,-,--) ; 323.2 \mathrm{~K}:(\bullet, \bigcirc,-,--) ; 333.2 \mathrm{~K}:(\Delta, \triangle,-,--)$. Symbols represent experimental results, full the liquid phase and open the vapor phase. Lines represent the correlation with the Peng-Robinson equation of state using two different mixing rules, van der Waals $\left(\mathrm{k}_{12} \neq 0\right.$ and $\left.\mathrm{l}_{12}=0\right)(-)$. and Wong-Sandler plus Non-Random Two Liquid model $(--)$. 


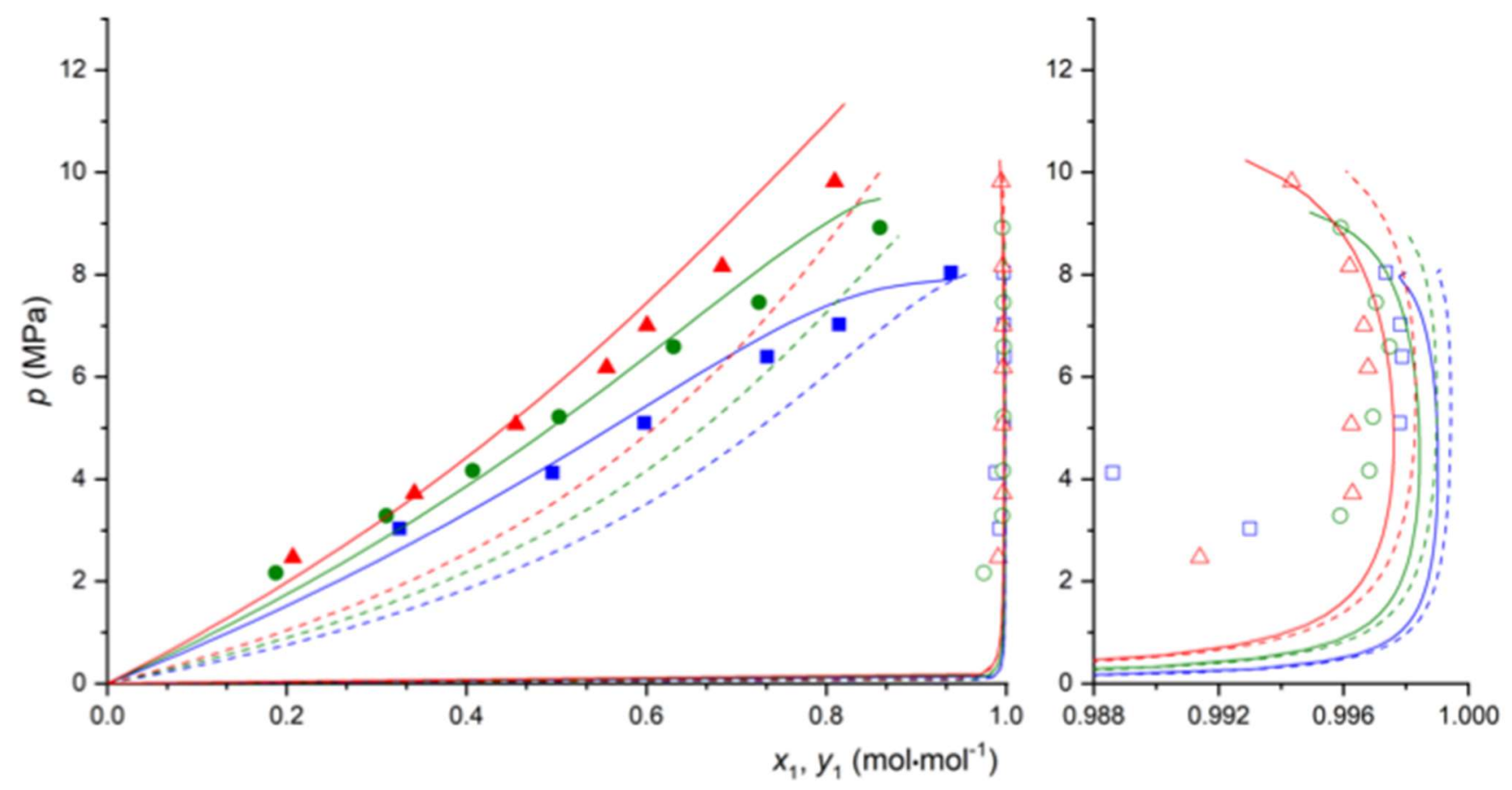

Figure 3. Isothermal vapor + liquid equilibria for the binary system $\mathrm{CO}_{2}(1)+(E)-2$-hexenal (2) at temperatures of $313.2 \mathrm{~K}:(\square, \square,-,--)$; $323.2 \mathrm{~K}:(\bullet, \bigcirc,-,--)$; $333.2 \mathrm{~K}:(\Delta, \triangle,-,--)$. Symbols represent experimental results, full the liquid phase and open the vapor phase. Lines represent the correlation with the Perturbed Chain - Statistical Associating Fluid Theory equation of state used as a predictive tool $\left(\mathrm{k}_{12}=0\right)(--)$, and as a correlation tool $\left(\mathrm{k}_{12}=0.0752\right)(-)$. 